Case Study

\title{
Dual task training effects on balance and hand functions of stroke patients
}

\author{
JUHYung PARK, MSc, OT ${ }^{1)}$ \\ 1) Department of Occupational Therapy, Health Science College, Cheongju University: \\ 298 Daesung-ro, Cheongwon-gu, Cheongju 363-764, Republic of Korea
}

\begin{abstract}
Purpose] The purpose of this research is to take a look at the influences of the dual task training on the hand function and the balance ability of the stroke patients. [Subjects and Methods] The dual task training was applied to 2 stroke hemiplegia patients. The dual task training had been carried out for 30 minutes by each session for 5 days a week for 3 weeks. The evaluations had been carried out 5 times for 3 weeks before and after the intervention. And the changes of the hand function had been measured by using the box and block test. And, for the changes of the balancing ability, the Berg Balance Scale was used. [Results] Both the hand function and the balancing ability of the subjects were improved after the dual task training. [Conclusion] Through the results of the research, it was able to confirm that the dual task training is effective for the enhancements of the hand function and the balancing ability of the stroke patients.

Key words: Dual-task training, Hand function, Stroke
\end{abstract}

(This article was submitted May 27, 2017, and was accepted Jul. 7, 2017)

\section{INTRODUCTION}

Dual-tasking training means carrying out a yet another task while carrying out one task or continuously carrying out two or more tasks at the same time ${ }^{1}$. Such a dual-tasking training is a very effective intervention for helping with the actual rehabilitation of the stroke patients in the situation in which most of the many activities that take place generally in the everyday life occur as 2 or more tasks ${ }^{2}$. Also, it was reported that, with regard to the neurological aspect and the dual-tasking training, the training in the dual-tasking situation can show the positive results with the cerebral blood flow in the brain increasing more than in the trainings in the simple situations according to the results of a research by Erickson et al ${ }^{3}$.

The many, previous researches reported the effects of the dual-tasking training regarding the stroke patients. Silsupadol et al. reported that, as a result of applying the conditions of the single task and the dual tasks to the elderly who possess the balance damages, the significant improvements were shown with regard to the walking speed aspect in the experimental group in an experiment carried out under the dual-tasking condition after the training ${ }^{4}$ ). Other than this, in the many researches that applied the dual-tasking training to the stroke patients, the improvements of the trunk controlling ability and the balancing ability through the dual-tasking training were reported ${ }^{5,6}$. But, the actual circumstance is that the researches on the improvement of the manual function through an intervention with the applications of the dual-tasking training to the stroke patients are still insufficient. As such, in this research, it is intended to take a look at the influences of the dual-tasking training on the manual function and the balance of the stroke patients. 


\section{SUBJECTS AND METHODS}

The subjects of this research were the 2 persons who received the diagnosis of hemiplegia due to stroke and had been receiving the hospitalized treatment at Hospital A in Korea. The general characteristics of the subjects are noted in Table 1. The subject 1 was a male who was 62 years old. Because of the middle cerebral artery infarction, he had hemiplegia on the right side, and the illness period was 15 months. The subject 2 was a woman who was 60 years old. Because of the middle cerebral artery infarction, she had hemiplegia on the right side, and the illness period was 13 months. The major hand of both subject 1 and subject 2 before the occurrence of the illness was the right hand. And the conservative physical therapy and the occupational therapy were carried out for 30 minutes each for 5 times a week. All subjects and their guardians signed an informed consent form after receiving the information about the purpose and the method of the study. The criteria for selecting the subjects for the research were the following: A person who received the diagnosis of the hemiplegia due to stroke and has passed 6 months after the occurrence of the illness; A person whose score in the Mini Mental State Examination- Korean (MMSE-K) was 20 or higher, which is the degree with which the instructions of the researchers can be followed; a person who can independently walk for 5 minutes at a comfortable speed; and a person who does not have any neurological or orthopedic illnesses other than stroke. This study used an interrupted time series (ITS) design. The ITS designs are characterized by the collection of multiple observations over time that are "interrupted" by an intervention or treatment ${ }^{7)}$. The BBT is an evaluation tool that has been standardized for evaluating the dexterity of the arms. A strong point is that the evaluation with the measurement of the number of the pieces of wood that were moved within 1 minute is simple. Regarding the examinationreexamination reliability of this tool, it is 0.93 for the left hand and 0.97 for the right hand. And, regarding the reliability between the examiners, it is 0.99 for the left hand and 1.00 for the right hand ${ }^{8)}$. The BBS is an evaluation tool made by Berg et al. in 1989 in order to measure the functional, standing balance of the elderly. And the reliability between the examiners of this examination is 0.99 . And the reliability between the examiners is 0.98 . It is a tool that possesses the high reliability and validity ${ }^{9}$. The dual-tasking training program that had been applied to the subjects had been carried out 30 minutes by session for 5 times in the total of 3 weeks. And it is organized with the activities that must be carried out simultaneously which are the activities for the improvement of the balance adjustments in the unstable supporting surfaces and the activity for the improvement of the hand function. The contents of the individual programs were a total of 3 kinds. They were piling up the cups, cleaning the mirrors, and inserting the light books on an unstable supporting surface using a health airboard. To help the understanding of the subjects, the demonstrations and the explanations by the therapists were preceded before carrying out the activities. And the dual task trainings were carried out when the subjects expressed that they completely understood the training process. The data analysis included a descriptive analysis of the mean differences to test whether this dual-task training had a larger positive effect on the impairment than that of the natural recovery. For each participant, the individual pre-intervention data points were used to determine a mean pre-intervention score for each measure; and the same procedure was followed to obtain the mean post-intervention scores.

\section{RESULTS}

The before scores, the after scores, and the mean difference scores for all the measurements are presented in Table 2. Regarding the subjects, the positive changes appeared in most items.

Table 1. General characteristic of the subjects

\begin{tabular}{lcccccc}
\hline & Age & Gender & Diagnosis & Affected side & Dominant hand $\begin{array}{c}\text { Months after } \\
\text { stroke onset }\end{array}$ & MMSE-k \\
\hline Participant 1 & 62 & Male & Ischemic & Rt. & Rt. & 15 \\
Participant 2 & 60 & Female & Ischemic & Rt. & Rt. & 13 \\
\hline
\end{tabular}

Table 2. Mean pre- and post-intervention scores and mean difference

\begin{tabular}{lccc}
\hline Measure & Preintervention Mean & Postintervention Mean & Mean Difference \\
\hline BBT & & & \\
Participant 1 & 12.0 & 19.0 & 7.0 \\
Participant 2 & 13.6 & 17.4 & 3.8 \\
BBS & & & \\
Participant 1 & 78.0 & 84.0 & 6.0 \\
Participant 2 & 68.0 & 72.0 & 4.0 \\
\hline
\end{tabular}




\section{DISCUSSION}

The purpose of this research was to apply the dual-tasking training that is nearer to the everyday life, in which the simultaneous carrying out of the even more diverse tasks is demanded, by doing away with the simple task training that has been taking place clinically generally with the stroke patients as the subjects and to verify the therapeutic effectiveness with regard to the balancing ability of the patients and the aspect of the enhancement of the hand function. As a result, the enhancements of the manual functions and the balancing capabilities of the stroke patients through the dual-tasking training could be observed. Such a result means that the previous dual-tasking training can have the positive influence on the improvement of the manual function other than the result of the research that the previous dual-tasking training has the positive influences on the walking abilities of the stroke patients, the trunk controlling ability, and the balancing ability ${ }^{4-6}$. But, as for the limitations of this research, there are the points that, as a matter of the special characteristic of the case example research, because the number of the subjects is small, there is the difficulty in generalizing the results and the points that, because the brain imaging technique like the fMRI and the PET were not used, the direct changes of the brain could not be confirmed through this research. It is thought that, in the future researches, there is a need to carry out the researches by supplementing such limitations.

\section{REFERENCES}

1) Pellecchia GL: Dual-task training reduces impact of cognitive task on postural sway. J Mot Behav, 2005, 37: 239-246. [Medline] [CrossRef]

2) Yang YR, Wang RY, Chen YC, et al.: Dual-task exercise improves walking ability in chronic stroke: a randomized controlled trial. Arch Phys Med Rehabil, 2007, 88: 1236-1240. [Medline] [CrossRef]

3) Erickson KI, Colcombe SJ, Wadhwa R, et al.: Training-induced functional activation changes in dual-task processing: an FMRI study. Cereb Cortex, 2007, 17: 192-204. [Medline] [CrossRef]

4) Silsupadol P, Lugade V, Shumway-Cook A, et al.: Training-related changes in dual-task walking performance of elderly persons with balance impairment: a double-blind, randomized controlled trial. Gait Posture, 2009, 29: 634-639. [Medline] [CrossRef]

5) Bowen A, Wenman R, Mickelborough J, et al.: Dual-task effects of talking while walking on velocity and balance following a stroke. Age Ageing, 2001, 30: 319-323. [Medline] [CrossRef]

6) Bensoussan L, Viton JM, Schieppati M, et al.: Changes in postural control in hemiplegic patients after stroke performing a dual task. Arch Phys Med Rehabil, 2007, 88: 1009-1015. [Medline] [CrossRef]

7) Park J, Lee N, Cho Y, et al.: Modified constraint-induced movement therapy for clients with chronic stroke: interrupted time series (ITS) design. J Phys Ther Sci, 2015, 27: 963-966. [Medline] [CrossRef]

8) Desrosiers J, Bravo G, Hébert R, et al.: Validation of the Box and Block Test as a measure of dexterity of elderly people: reliability, validity, and norms studies. Arch Phys Med Rehabil, 1994, 75: 751-755. [Medline]

9) Bogle Thorbahn LD, Newton RA: Use of the Berg Balance Test to predict falls in elderly persons. Phys Ther, 1996, 76: 576-583, discussion 584-585. [Medline] [CrossRef] 